\title{
Transvaginal Ultrasound Diagnosis of Polycystic Ovarian Syndrome and its Correlation with Biochemical Parameters
}

\author{
Arpitha K J1, Ravi $\mathbf{N}^{2}$ \\ ${ }^{1}$ Post Graduate, Department of Radiodiagnosis, ${ }^{2}$ Professor, Department of Radiodiagnosis, Bangalore Medical College and \\ Research Institute, India
}

Corresponding author: Arpitha K J, Post Graduate, Department of Radiodiagnosis, Bangalore Medical College and Research Institute, India

DOI: http://dx.doi.org/10.21276/ijcmsr.2020.5.2.6

How to cite this article: Arpitha K J, Ravi N. Transvaginal ultrasound diagnosis of polycystic ovarian syndrome and its correlation with biochemical parameters. International Journal of Contemporary Medicine Surgery and Radiology. 2020;5(2):B21-B26.

\section{A B S T R A C T}

Introduction: Polycystic ovarian syndrome is a heterogeneous endocrine disorder affecting women of reproductive age group characterized by a combination of polycystic ovarian morphology, clinical features and biochemical indices. The objective of this study was to identify the sonological features of ovaries and endometrium and to correlate with clinical and biochemical profile of the patients with PCOS.

Material and methods: Transvaginal ultrasonography was performed in the patients clinically suspected of having polycystic ovarian syndrome and their biochemical parameters were determined. Statistical analysis included only those patients having complete data.

Results: Among 104 patients, the mean age was 26 years, Maximum cases were seen in the age group of 26-30 years. Menstrual irregularities (91.3\%) and infertility (51\%) were the most common complaint. Other complaints were obesity, hirsutism and acne in the descending order. Pelvic sonography identified $75 \%$ of patients with bulky ovary ( $>10 \mathrm{cc}$ ), peripherally arranged follicles $98 \%$ of patients, $\geq 12$ follicles per ovary in $82 \%$ and $2-9 \mathrm{~mm}$ follicles in $90 \%$. The range of stromal thickness was 7.5 to $10 \mathrm{~mm}$ and $\geq 10 \mathrm{~mm}$ in $72 \%$ cases.

Conclusion: The sonological ovarian features in patients with clinical suspicion of Polycystic ovarian syndrome correlated well with clinical and biochemical indices in Statistically significant numbers.

Keywords: Biochemical Parameters; Polycystic Ovarian Syndrome; Transvaginal Ultrasound

\section{INTRODUCTION}

Polycystic ovarian syndrome (PCOS) is a complex endocrinologic disorder of abnormal estrogen and androgen production affecting women of reproductive age group, characterized by combination of polycystic ovarian morphology, clinical features and biochemical indices. Polycystic ovarian syndrome starts appearing at 15 to 25 years of age and it may take upto 35-40 years for its clinical presentation. ${ }^{1}$

World Health Organization (WHO) estimates that PCOS has affected 116 million women (3.4\%) globally. World wide, prevalence are highly variable, ranging from $2.2 \%$ to as high as $26 \%$. In India, approxmimately $10 \%$ of the women to be affected by PCOS. ${ }^{2}$ The incidence of polycystic ovarian syndrome is $50 \%$ of women at infertility clinics. ${ }^{3}$

Women with polycystic ovarian syndrome are presented with three main clinical reasons. menstrual irregularities (mean incidence of 70\%), Infertility (mean incidence 40\%) and androgen excess (mean incidence of Hirsuitism 70\%, acne 15 to $30 \%){ }^{4}$

Irving Stein and Michael Leventhal first described Polycystic ovarian syndrome in 1935 in a group of patients presenting with clinical features of amenorrhea, bilateral polycystic ovaries, and hirsutism change. Initially they thought this is due to harmonal variation related to pituitary. ${ }^{5}$

PCOS is characterized by low follicle stimulating hormone levels and elevated luteinizing hormone levels. Low FSH lavels resulting in anovulation, elevated LH levels resulting in hyperandrogenism, and insulin-resistance symptoms which may range from simple cystic acne, cephalic hair loss, or mild facial hirsutism to instances of oligomenorrhoea or amenorrhoea, sterility and severe generalized hirsutism.

Further in 1970s, development of pelvic ultrasonography added diagnostic specificity to the recognition of PCOS. In 2003 Ultrasound diagnostic criterion following the Rotterdam Consensus meeting for PCOS diagnosis were made ${ }^{6}$

American Association Of Clinical Endocrinologist (AACE) And Androgen Excess And PCOS Society(AES) 2015 guidelines that the diagnosis of PCOS must be based on the presence of at least two of the following three criteria:

- Chronic anovulation

- Hyperandrogenism

- Polycystic ovaries with exclusion of other etiologies

The criteria to define the polycystic ovaries as follows: 12 
or more small follicles ( 2 to $9 \mathrm{~mm}$ ) in the whole ovary and Increased ovarian volume $(>10 \mathrm{cc})$. This presentation in one ovary significantly defines the polycystic ovary. ${ }^{7}$

Thus Polycystic ovarian syndrome has evolved through many steps from the clinical, biochemical and imaging perspectives. Further transvaginal sonography, have qualitatively enhanced the information on the internal structure of ovary and endometrial morphology. With this background, the present study was undertaken to identify and assess the sonological features in patients with clinical and biochemical features of polycystic ovarian syndrome

\section{MATERIAL AND METHODS}

Female Patient in age group 18-35 years were referred from department of obstetrics and gynaecology of Bangalore medical college and research institute with attached Vanivilas, Victoria and Bowring and lady Curzon hospitals for pelvic ultrasonography in clinical suspicion of PCOS were included in this study. The study period was eighteen months from November 2017 to May 2019.

A prospective study of 104 female patients in reproductive age group was done for evaluation of ovarian morphology and endometrium by pelvic by transvaginal and transabdominal ultrasonography. The patient blood samples were sent for biochemical analysis- Serum LH, FSH, AMH, RBS, Testosterone, TSH levels.

\section{Inclusion Criteria}

- Female patient in reproductive age group(18-35)

- Infertility (Inability of couple to achieve conception after one year of unprotected coitus)

- Oligomenorrhoea (cycle lasts longer than 35 days)

- Hirsutism (presence of terminal hairs in female in a male like pattern)/Acne

- Obesity $\left(\mathrm{BMI}>30 \mathrm{~kg} / \mathrm{m}^{2}\right)$

- Patient agrees to give consent to undergo transvaginal ultrasonography.

\section{Exclusion Criteria}

- Known case of polycystic ovarian syndrome on treatment and follow up

- $\quad$ Patients age $<18$ years and $>35$ years

- Patient refuses to give consent

- Patient without hormonal investigations

- Known case of endocrinological disorder

- Patients with other co-morbidities which can alter the hormonal profile.

- Unmarried patients where transvaginal ultrasonography is contraindicated.

- Patient lost for follow up.

\section{Transvaginal Ultrasonography}

The study was performed using PHILIPS A35 using curved probes of frequency ranging from 7 to $10 \mathrm{MHZ}$.

Preparation and the procedure included:

- Patient was asked to empty the bladder as completely as possible.

- A clean transducer covered with condom after gel has been placed on the transducer tip.

- Patient was positioned supine.

- The probe was advanced 3 to 4 inches into the vagina.
- Sagittal and coronal images of the uterus and ovaries were obtained.

\section{Transabdominal Ultrasonography}

The study was performed using PHILIPS A35 using convex probes of frequency ranging from 3 to $5 \mathrm{MHZ}$.

\section{Preparation and the procedure included}

- Patients were advised to drink water

- The patients were asked not to void at least for one hour before the examination

- The scan was performed when the urinary bladder was sufficiently distended.

- The scan was performed with the patients in supine position and with abdomen and pelvis adequately exposed.

- The scan was done both in longitudinal and transverse plane, and images were obtained.

\section{STATISTICAL ANALYSIS}

Data was entered into Microsoft excel data sheet and was analyzed using SPSS 22 version software. Categorical data was represented in the form of frequencies and proportions. For qualitative data, Chi-square test was used as test of significance. Continuous data was represented as mean and standard deviation. $\mathrm{P}$ value (Probability that the result is true) of $<0.05$ was considered as statistically significant after assuming all the rules of statistical tests.

\section{RESULTS}

\section{Age distribution of PCOS subjects in the study}

In the study $25 \%$ were in the age group 18 to 25 years, $54.8 \%$ were in the age group 26 to 30 years and $20.2 \%$ were in the age group 31 to 35 years.

\section{Complaints of PCOS subjects distribution}

In the study $91.3 \%$ had menstrual irregularities, $51 \%$ had infertility, $1.9 \%$ had acne, $11.5 \%$ had Hirsutism and $17.3 \%$ had obesity.

\section{BMI distribution of PCOS subjects}

In the study 5.8\% had BMI <20,32.7\% had BMI 21 to 25, $42.3 \%$ had BMI 26 to 30 and 19.2\% had BMI 31 to 39.

Ultrasound features distribution among PCOS subjects

- In the study $26 \%$ had ovarian volume of $<10 \mathrm{cc}$ and $74 \%$ had ovarian volume of $>10 \mathrm{cc}$.

- $\quad 98.1 \%$ had peripheral (Figure 1) and 1.9\% had irregular arrangement of follicles.

$17.3 \%$ had $<12$ follicles and $82.7 \%$ had $>12$ follicles.

- $\quad 90.4 \%$ had 2 to $9 \mathrm{~mm}$ follicle size and $9.6 \%$ had $>9 \mathrm{~mm}$ follicle size.

- $\quad 27.9 \%$ had $<10 \mathrm{~mm}$ and $72.1 \%$ had $>10 \mathrm{~mm}$ ovarian stroma.

- $\quad 91.3 \%$ had normal endometrium, 6.7\% had thickened and homogenous endometrium and $1.9 \%$ had thickened and heterogeneous endometrium

Hormonal profile distribution among PCOS subjects

- $\quad$ In the study $24 \%$ had $<15 \mathrm{mIU} / \mathrm{ml}$ and $76 \%$ had $>15$ $\mathrm{mIU} / \mathrm{ml}$ of $\mathrm{LH}$.

- $\quad 91.3 \% \mathrm{had}<10.5 \mathrm{mIU} / \mathrm{ml}$ and $8.7 \% \mathrm{had}>10.5 \mathrm{mIU} / \mathrm{ml}$ FSH. 

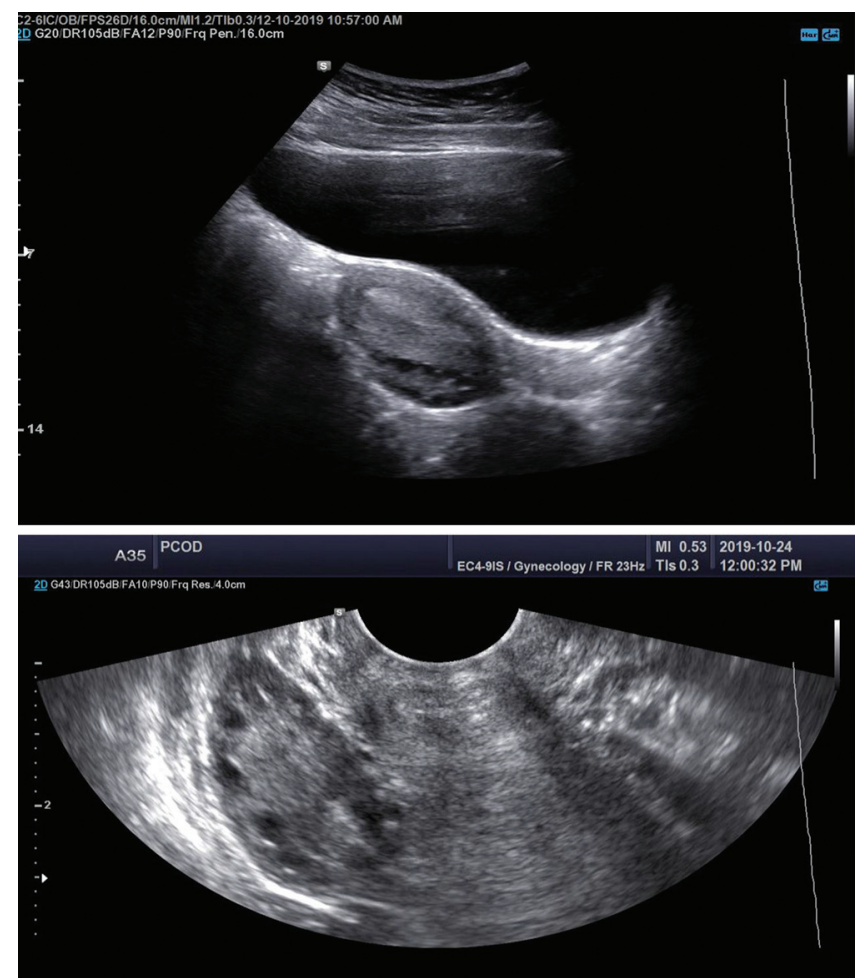

Figure-1: TAS (A) - Bulky ovary with multiple peripherally arranged follicles and thickened endometrium and TVS (B) -Bulky ovary with multiple peripherally arranged follicles

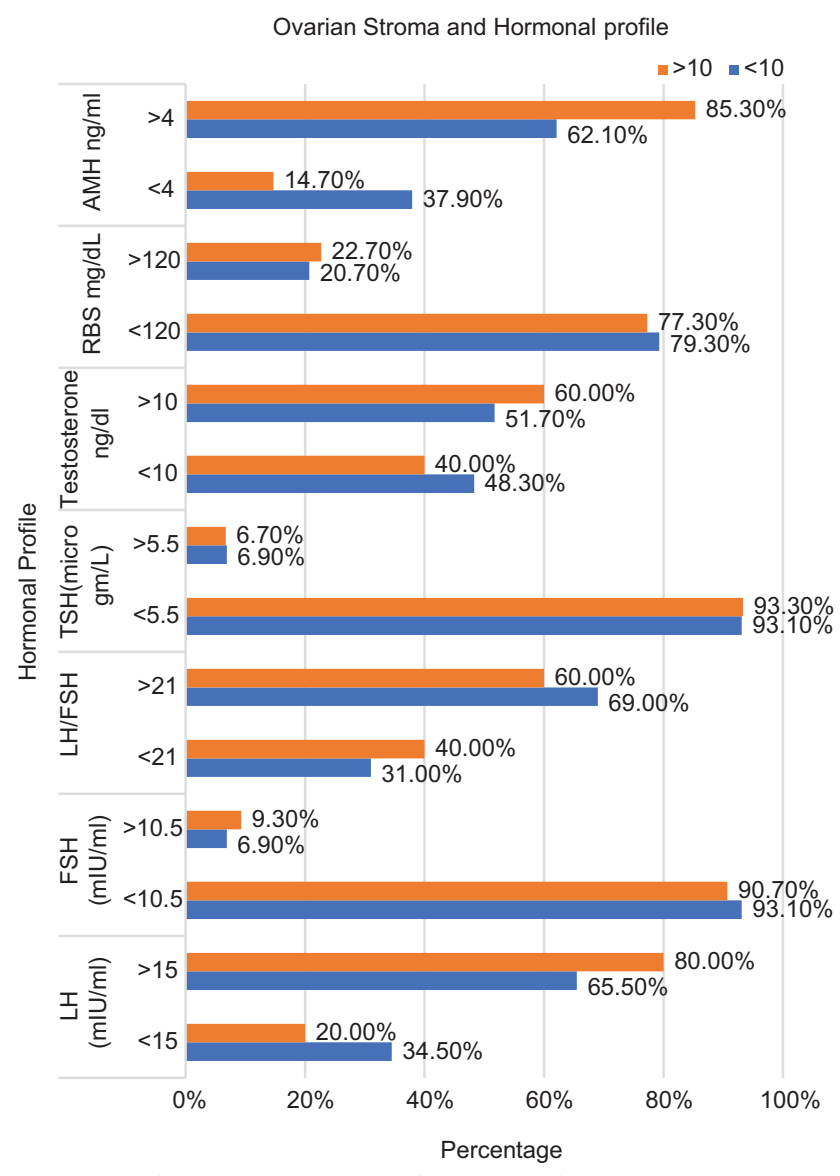

Figure-2: Column Diagram Showing Correlation between Ovarian Stroma and Hormonal profile

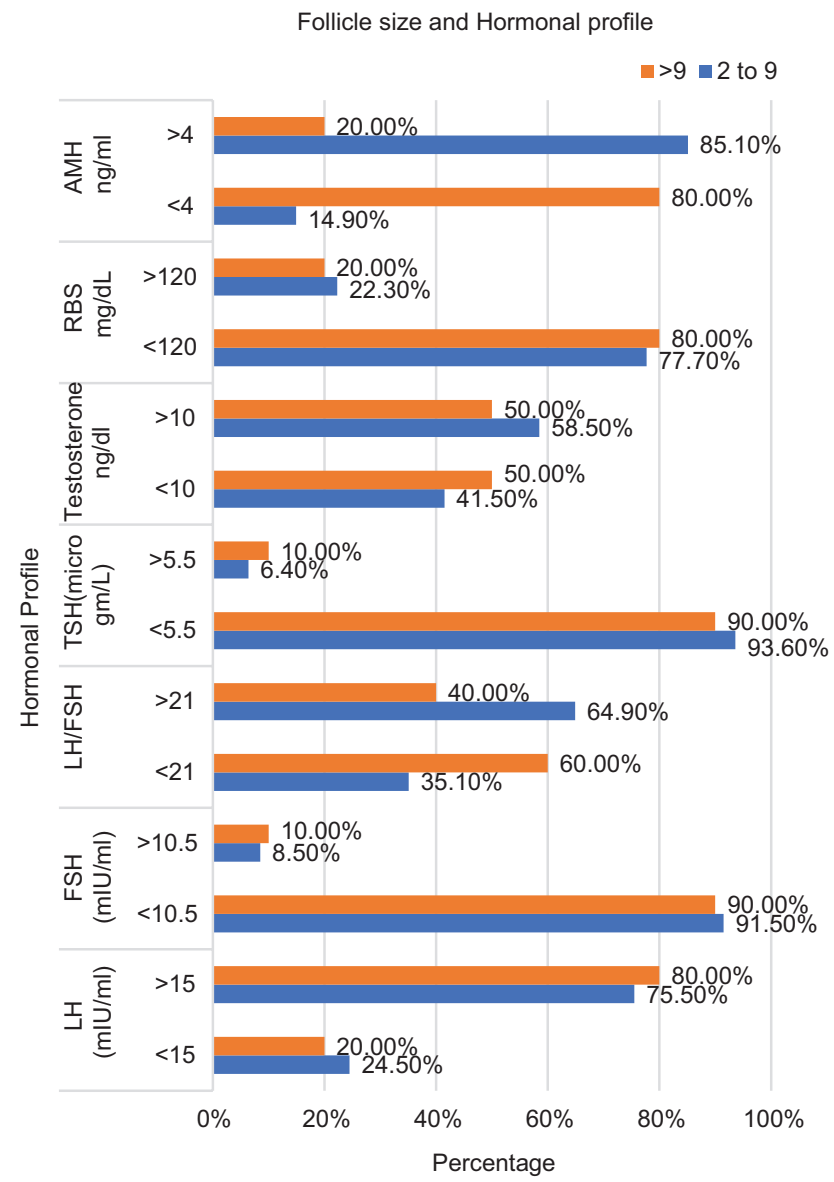

Figure-3: Column Diagram showing Correlation between Follicle size and Hormonal profile

- $\quad 37.5 \%$ had $<21$ and $62.5 \%$ had $>21 \mathrm{LH} / \mathrm{FSH}$.

- $\quad 93.3 \% \mathrm{had}<5.5$ micro $\mathrm{gm} / \mathrm{L}$ and $6.7 \% \mathrm{had}>5.5 \mathrm{micro}$ $\mathrm{gm} / \mathrm{L} \mathrm{TSH}$.

- 42.3\% had $<10 \mathrm{ng} / \mathrm{dl}$ and $57.7 \% \mathrm{had}>10 \mathrm{ng} / \mathrm{dl}$ Testosterone.

- $77.9 \%$ had $<120 \mathrm{mg} / \mathrm{dl}$ and $22.1 \% \mathrm{had}>120 \mathrm{mg} / \mathrm{dl}$ RBS and $21.2 \% \mathrm{had}<4 \mathrm{ng} / \mathrm{ml}$ and $78.8 \% \mathrm{had}>4 \mathrm{ng} / \mathrm{ml}$ $\mathrm{AMH}$.

\section{Correlation between ultrasound features and Hormonal profile}

- In the study there was no significant difference in $\mathrm{LH}$, FSH, LH/FSH, TSH, Testosterone, RBS and AMH with respect to ovarian volume.

- In the study there was no significant difference in LH, FSH, LH/FSH, TSH, Testosterone and AMH with respect to Arrangement of Follicles except for RBS levels.

Among those with peripheral follicles 20.6\% had $>120 \mathrm{mg} / \mathrm{dl}$ RBS, were as among those with irregular arrangement of follicles, $100 \%$ had $>120 \mathrm{mg} / \mathrm{dl}$ RBS. This difference was statistically significant.

- In the study there was no significant difference in LH, FSH, LH/FSH, TSH, Testosterone and RBS with respect to Ovarian stroma except for AMH levels.

Among those with $<10 \mathrm{~mm}$ Ovarian Stroma, 62.1\% had $>4 \mathrm{ng} / \mathrm{ml}$ AMH, were as among those with $>10$ $\mathrm{mm}$ Ovarian Stroma, 85.3\% had $>4 \mathrm{ng} / \mathrm{ml}$ AMH. This difference was statistically significant (Figure 2). 


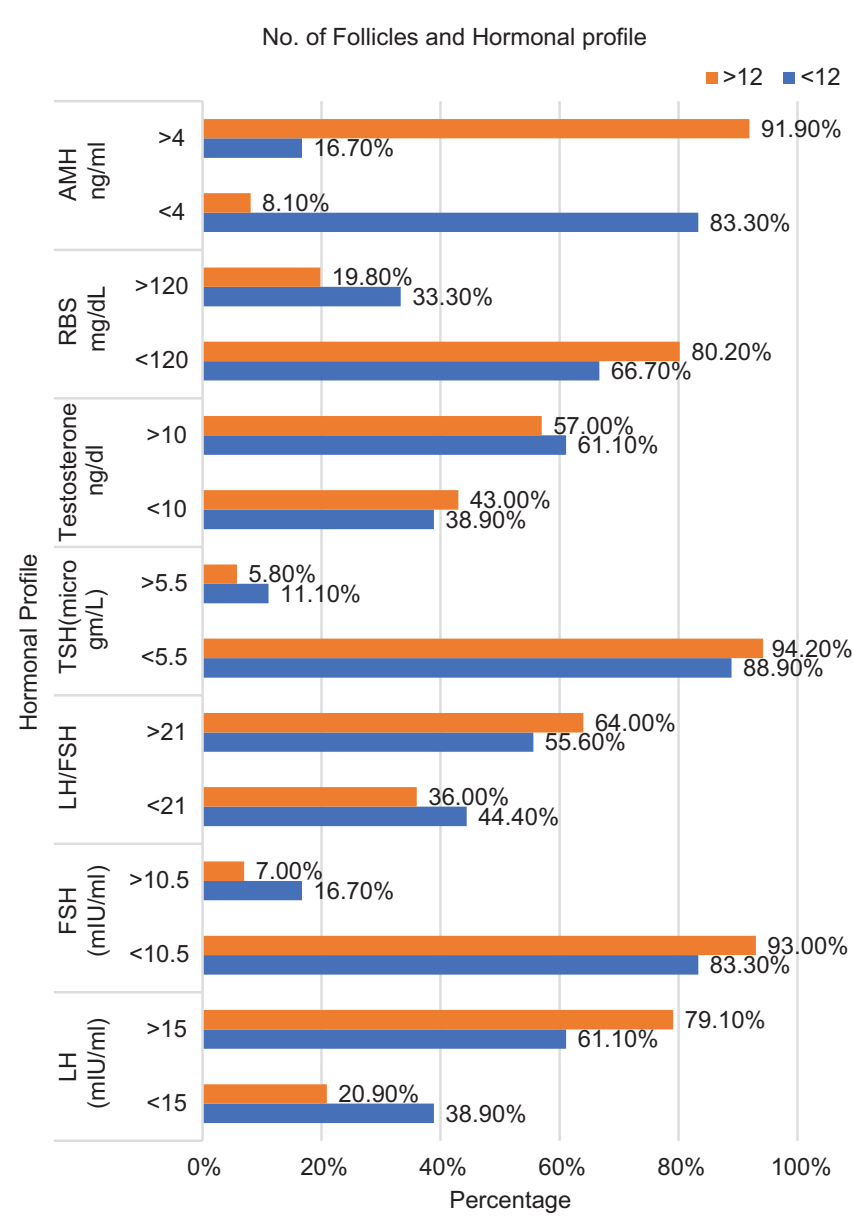

Figure-4: Column Diagram showing Correlation between Number of Follicles and Hormonal profile

- In the study there was no significant difference in LH, FSH, LH/FSH, TSH, Testosterone and RBS with respect to Follicle size except for $\mathrm{AMH}$ levels.

Among those with 2 to $9 \mathrm{~mm}$ follicle size, $85.1 \%$ had $>4 \mathrm{ng} / \mathrm{ml} \mathrm{AMH}$, were as among those with $>9 \mathrm{~mm}$ follicle size, $20 \% \mathrm{had}>4 \mathrm{ng} / \mathrm{ml}$ AMH. This difference was statistically significant (Figure 3 ).

- In the study there was no significant difference in LH, FSH, LH/FSH, TSH, Testosterone and RBS with respect to number of Follicles except for $\mathrm{AMH}$ levels.

Among those with $<12$ follicles, $16.7 \%$ had $>4 \mathrm{ng} / \mathrm{ml}$ $\mathrm{AMH}$, were as among those with $>12$ follicles, $91.9 \%$ had $>4 \mathrm{ng} / \mathrm{ml} \mathrm{AMH}$. This difference was statistically significant (Figure 4).

In the study there was no significant difference in $\mathrm{LH}, \mathrm{FSH}$, $\mathrm{LH} / \mathrm{FSH}, \mathrm{TSH}$, Testosterone, RBS and AMH with respect to Endometrial thickness.

\section{DISCUSSION}

Age wise distribution of the patients

Out of 104 patients studied, the mean age of presentation was 26 years. The age range observed was between 18 years to 35 years. In the study $25 \%$ were in the age group 18 to 25 years, $54.8 \%$ were in the age group 26 to 30 years and $20.2 \%$ were in the age group 31 to 35 years. Maximum cases were seen in the age group of 26-30 years.
In study by S.Jonard, Y. Robert ${ }^{8}$ the age range was 21 to 34 years with a median age of 27 years. It is a prospective study of 214 patients of polycystic ovarian syndrome. Range of age was 14 to 37 years with a mean age of 24 years in a study of 104 patients diagnosed as having polycystic ovarian syndrome by Hsu-Chong Yeh and Walter Futterweit.9

\section{Chief complaints of the patients}

In the present study In the study $91.3 \%$ had menstrual irregularities, 51\% had infertility, $1.9 \%$ had acne, $11.5 \%$ had Hirsutism and $17.3 \%$ had obesity. These observations were similar to the study by Adams et al and Luciano G. Nardo et $\mathrm{a}^{10}$ In this study along with oligomenorrhea (100\%), infertility (85\%) and hirsutism (65\%) were the main complaints of the patients with polycystic ovarian syndrome.

\section{BMI distribution}

In the present study $5.8 \%$ had BMI $<20,32.7 \%$ had BMI 21 to $25,42.3 \%$ had BMI 26 to 30 and $19.2 \%$ had BMI 31 to 39 . The range of BMI was 18 to $39 \mathrm{~kg} / \mathrm{m} 2$ with mean 28 $\pm 6 \mathrm{~kg} / \mathrm{m} 2$. This study results were similar from the study by Insler $\mathrm{V}$ and Shoham $\mathrm{Z}^{11}$ which showed $50 \%$ of the patients were obese with BMI > $25 \mathrm{~kg} / \mathrm{m} 2$.

\section{Volume of the ovary}

The volume range observed in the present study was between 7 to $14 \mathrm{~mm}$. When $\geq 10 \mathrm{cc}$ was taken as the criteria for polycystic ovarian syndrome according to Rotterdam consensus meeting, this study was observed $\geq 10 \mathrm{cc}$ volume in most (74\%) of the patients and in $26 \%$ the volume was less than $10 \mathrm{cc}$. Hann et $\mathrm{al}^{12}$ study showed $\geq 10 \mathrm{cc}$ in $71 \%$ and normal ovarian volume in about $29 \%$.

\section{Arrangement of follicles}

In the study $98.1 \%$ had peripheral and $1.9 \%$ had irregular arrangement of follicles.

This observation was seen in Ardaens $\mathrm{Y}^{14}$ 55\% in irregular and scattered, $45 \%$ in peripheral distribution, Hann LE 73\% in peripheral distribution.

\section{Number of follicles per ovary}

The range of follicle number observed in the present study was between 10 and 20 , with a mean of $12 \pm 2$. Maximum numbers of patients $(82.7 \%)$ were in the group of $\geq 12$ follicles, $17.3 \%$ showed $<12$ follicles. This cut off point was taken as per the Rotterdam consensus definition of polycystic ovarian syndrome. If the cut off point was $\geq 10$ follicles following the criteria of Adams et $\mathrm{al}^{13} 100 \%$ of the patients in the present included in this group.

\section{Follicle size}

The range of follicle size in this study was between 2 to 12 $\mathrm{mm}$. Mean size observed was $5.5 \mathrm{~mm}$. Most common size range observed in this study was $2-9 \mathrm{~mm}$ which was seen in $90.4 \%$ of the patients. $>9 \mathrm{~mm}$ follicles were seen in $9.6 \%$ of the patients and $<2 \mathrm{~mm}$ in none. This could be because of the insensitivity of the ultrasound machine to detect the follicles less than $2 \mathrm{~mm}$.

This observation was supported by other studies by Adams, Polson et $\mathrm{al}^{13}$ whose studies observed $2-9 \mathrm{~mm}$ was the most common (> 60\%) follicular size in patients with polycystic ovarian syndrome. 


\section{Stromal thickness and character}

The subjective evaluation of the stroma in this present study showed echogenic and thickened $(>10 \mathrm{~mm})$ in $72.1 \%$ of the patients and non echogenic and thin $<10 \mathrm{~mm}$ ) in $27.9 \%$ of the patients. This observation was supported by Ardaens et $\mathrm{al}^{14}$, the quantitative measurement of the stromal thickness in this present study ranged between $2 \mathrm{~mm}$ to $14 \mathrm{~mm}$ with mean thickness $7 \mathrm{~mm}$.

\section{Endometrial thickness and character}

In the study 91.3\% had normal Endometrium, 6.7\% had thickened and homogenous Endometrium and 1.9\% had thickened and heterogeneous Endometrium.

The endometrial thickness was $3 \mathrm{~mm}-9 \mathrm{~mm}$ and homogenous in $91.3 \%$ of patients.This observation is comparable with the study by Nagamani Peri et $\mathrm{al}^{4}$ in which out of 245 patients with polycystic ovarian syndrome, about $93 \%$ had homogenous endometrium with thickening ranging from $1 \mathrm{~mm}-17 \mathrm{~mm}$ and the rest about $7 \%$ had heterogenous endometrium with thickness ranges from $4 \mathrm{~mm}$ to $23 \mathrm{~mm}$

\section{Correlation between ovarian features and hormonal profile}

There is a positive correlation between ovarian volume with raised $\mathrm{LH}(75.3 \%), \mathrm{LH} / \mathrm{FSH}(66.3 \%), \mathrm{AMH}$ (80.5\%) and reduced/normal FSH levels (93.5\%) But this association is not statistically significant.

There is a positive correlation between peripherally arranged follicles with raised LH (71.5\%), LH/FSH (62.7\%), AMH (80\%), reduced/normal FSH (91.2\%) and TSH (93.1\%) levels.But this association is not statistically significant.

There is a positive correlation between $>12$ follicles with raised $\mathrm{LH}$ (79.1\%), LH/FSH (64\%), AMH (91.1\%) and reduced/normal FSH (93.0\%) levels.But this association is not statistically significant.

There is a positive correlation between follicle size between $2-9 \mathrm{~mm}$ with raised $\mathrm{LH}$ (75.5\%), AMH (81.5\%) and reduced/normal FSH levels (91.5\%)But this association is not statistically significant except for AMH levels.

Among those with 2 to $9 \mathrm{~mm}$ follicle size, $85.1 \% \mathrm{had}>4 \mathrm{ng} /$ $\mathrm{ml} \mathrm{AMH}$, were as among those with $>9 \mathrm{~mm}$ follicle size, $20 \%$ had $>4 \mathrm{ng} / \mathrm{ml} \mathrm{AMH}$. This difference was statistically significant.

There is a positive correlation between thickened and echogenic ovarian stroma with raised LH (80.8\%), AMH (85.3\%), reduced/normal FSH (90.7\%) and TSH (93.3\%) levels.But this association is not statistically significant except for AMH levels.

Among those with $<10 \mathrm{~mm}$ Ovarian Stroma, 62.1\% had $>4$ $\mathrm{ng} / \mathrm{ml} \mathrm{AMH}$, were as among those with $>10 \mathrm{~mm}$ Ovarian Stroma, $85.3 \%$ had $>4 \mathrm{ng} / \mathrm{ml} \mathrm{AMH}$. This difference was statistically significant.

\section{Endometrium and Hormonal profile.}

There is a positive correlation between normal endometrial thickness with raised $\mathrm{LH}$ (73.7\%), LH/FSH ratio (62.9\%), $\mathrm{AMH}$ (85.3\%), reduced/normal FSH (90.5\%) and TSH (92.6\%) levels.

In the study there was no statistically significant difference in LH, FSH, LH/FSH, TSH, Testosterone, RBS and AMH with respect to Endometrial thickness.

\section{CONCLUSION}

There is significant increase in the incidence of young women with features of polycystic ovarian syndrome after the advent of ultrasound technique. The present study also showed PCOS in young women and $80 \%$ of the patients were below 30 years concurring with literature. Transvaginal sonography is more sensitive and accurate in the diagnosis. Transabdominal sonography can be recommended as a convenient imaging tool to identify ovarian morphology in any population group, but however transvaginal ultrasound has better sensitivity for identifying number of follicles, follicle size, endometrial pathology and stromal changes. With only transabdominal sonography there are chances of under and over diagnosis of polycystic ovaries. The diagnosis of polycystic ovarian disease should be considered only after transvaginal scan and its correlation with biochemical parameters.

\section{REFERENCES}

1. Belinda MS, Richard PD. Polycystic ovarian syndrome and the metabolic syndrome. Am J Med Sci 2005;330(6):336-342.

2. Inan $\mathrm{C}$, Karadag C. Correlation between ovarian morphology and biochemical and hormonal parameters in polycystic ovary syndrome. Pak J Med Sci. 2016;32(3):742-745

3. Nagamani Peri, Deborah Levine. Sonographic evaluation of the endometrium in patients with a history or an appearance of polycystic ovarian syndrome. J Ultrasound Med 2007; 26(4): 55-58.

4. Takahashi K, Eda Y, Abu Musa A, Okada S, Yoshino K, Kitao M. Transvaginal ultrasound imaging, histopathology and endocrinopathy in patients with polycystic ovarian syndrome. Human Reproduction 1994; 9(3):1231-1236.

5. Abdel Gadir A, Khatim MS, Mowafi RS, Alnaaser HM, Muharib NS, Shaw RW. Implications of ultrasonically diagnosed polycystic ovaries. Its correlations with basal hormonal profiles. Human reproduction 1992;7(4): 453-460.

6. Adam HB, Joop SE, Seang-Lin Tan, Didier Dewailly. Ultrasound assessment of the polycystic ovary: international consensus definitions. Human Reproduction Update 2003; 9(6):505-514.

7. Goodman NF, Cobin RH, Futterweit W, Glueck JS, Legro RS, Carmina E. American association of clinical endocrinologist, american college of endocrinology, and androgen excess and PCOS society disease state clinical review: guide to the best practices in the evaluation and treatment of polycystic ovarian syndrome-part 1 . Endocr Pract. 2015;21(11):1291-300.

8. Jonard S, Robert Y, Cortet-Rudelli C, Pigny P, Decanter C, Dewailly D. Ultrasound examination of polycystic ovaries: is it worth counting the follicles? Human reproduction 2003; 18(6):598-603.

9. Hsu-Chong Yeh, Walter Futterweit, John Thornton C. Polycystic ovarian disease: US features in 104 patients. Radiology 1987;163(3):111-116.

10. Luciano GN, William Buckest M, Daviana White, Alessandro Digesu G, Stephen Franks, Vik Khullar. Three dimensional assessment of ultrasound features 
in women with Clomiphene citrate-resistant polycystic ovarian syndrome (PCOS): ovarian stromal volume does not correlate with biochemical indices. Human reproduction 2002; 17(1):1052-1055.

11. Insler V, Shoham Z, Baraash A, Koistinen R, Seppala M, Hen M,Lunenfeld B, Zadik Z. Polycystic ovaries in nonobese and obese patients: possible pathophysiological mechanism based on new interpretation of facts and findings. Human Reproduction 1993; 8(3):379-84.

12. Hann LE, Hall DA, Mc Ardle CR, Seibel M. Polycystic ovarian disease: sonographic spectrum. Radiology 1984; 150(2): 531-534.

13. Adams J, Polson DW, Abdul wahid N, Morris DV, Franks S, Mason HD, et.al. Multifollicular ovaries: clinical and endocrine features and response to pulsatile gonadotropin releasing harmone. Lancet 1985; 2(4): 1375-1379.

14. Ardaens Y, Robert Y, Lemaitre L, Fossati P, Dewailly D. Polycystic ovarian disease-contribution of vaginal endosonography and reassessment of ultrasonic diagnosis, Fertil Steril 1991;55(6):1062-1068.

Source of Support: Nil; Conflict of Interest: None

Submitted: 20-02-2020; Accepted: 15-03-2020; Published online: 10-05-2020 